\title{
Ammonia and DMMP Sensor based on Nanostructured ZnO Thick
}

\section{Films}

\author{
Bari AR ${ }^{1 *}$, Bari PA${ }^{1}$, Bari RH${ }^{2}$ and Patil LA ${ }^{3}$ \\ ${ }^{1}$ Department of Physics, Arts, Commerce and Science College, Bodwad, Maharashtra, \\ India
}

${ }^{2}$ Nanomaterials Research Lab, Department of Physics, GDM Arts, KRN Commerce and M

D Science College, Jamner, Maharashtra, India

${ }^{3}$ Nanomaterials Research Lab, Department of Physics, Pratap College, Amalner, Maharashtra, India

*Corresponding author: Anil R Bari, Department of Physics, Arts, Commerce and Science College, Bodwad, 425 310, Maharashtra, India, Tel: +919421523832; Email: anilbari_piyu@yahoo.com

\section{Abstract}

Nanostructured zinc oxide powder was prepared using the ultrasonic atomization technique. This powder was collected using simple indigenous glass trapping system attached to ultrasonic system. Thick films of this powder were prepared using simple screen printing technique. The films were characterized using XRD, TEM, SEM and EDAX to know structure, size of crystallites, microtopography and elemental analysis respectively. The conventional gas and simulants of chemical warfare agents sensing performances of these films were tested. The thick film sensor was found to be most sensitive to $\mathrm{NH}_{3}$ (conventional gas) and DMMP (simulant of chemical warfare agents) respectively. The results were discussed and interpreted.

Keywords: Ultrasonic Atomization; Nanocrystalline ZnO; Thick Films; Sensor, Response; Response-Recovery Time

\section{Introduction}

$\mathrm{ZnO}$ is the most promising semiconductor to detect the toxic and hazardous gases [1]. Variety techniques have been used to prepare $\mathrm{ZnO}$ nanostructures: like sol-gel [2], metal organic chemical vapour deposition [3], dc magnetron sputtering [4], and spray pyrolysis [5] etc. Compared with these methods, ultrasonic spray pyrolysis is convenient and simple technique. Monitoring devices like sensors are in demand for a rapidly growing range of applications. Long life, small in size, low power consumption and easy fabrication are the main advantage of chemical sensors. Ammonia is harmful and toxic [6] in nature. The exposure of ammonia causes chronic lung disease, irritating and even burning the respiratory track, etc. It is therefore, needed to monitor ammonia gas and to develop the ammonia gas sensor.

The threat of attack from rogue nations and terrorist groups using chemical warfare agents (CWAs) and toxic industrial chemicals (TICs) is on the rise [7]. Thus, there exists an urgent need for reliable detectors and sensors for these classes of chemicals, to enable people to safely leave a contaminated zone or to protect themselves. Semiconducting metal oxide sensors are one of the most widely studied groups of chemiresistive gas sensors. Several materials are fabricated to enhance the sensing characteristics of the SMO CWA sensors with high 


\section{Nanomedicine \& Nanotechnology Open Access}

sensitivity to toxic, combustible gases and CWA [8]. The development of highly sensitive, selective, reliable, and compact sensing devices to detect flammable, toxic chemical and biological agents is of major importance. Over the last decades, Thick and thin film metal oxides have been widely studied for various gases [9].

In the present study, the nanocrystalline $\mathrm{ZnO}$ powder prepared from ultrasonic atomization technique. As prepared powder was studied using XRD, TEM, SEM and EDAX to know structure, size of crystallites associated with powder, microtopography and elemental analysis respectively. Thick film of this powder was prepared using screen printing technique. The conventional gas and simulant sensing performance of this film was tested.

\section{Experimental}

\section{Preparation of Nanocrystalline ZnO Powder and Thick Film Preparation}

The nanocrystalline $\mathrm{ZnO}$ powder was prepared by ultrasonic atomization and decomposition technique, the procedure of which has been explained elsewhere [10]. The thixotropic paste of nanocrystalline zinc oxide powder was formulated and thick films were prepared using screen printing technique on glass substrate in the desired pattern explain elsewhere [11]. The films were fired at $500^{\circ} \mathrm{C}$ for $30 \mathrm{~min}$ to remove the binder permanently.

\section{Characterizations}

\section{X-ray Diffractogram (XRD)}

(Figure 1) shows the $\mathrm{x}$-ray diffractogram of $\mathrm{ZnO}$ thick film. The observed peaks are matching well with the standard JCPDS data of $\mathrm{ZnO}$ [12]. The broad peaks are due to nanocrystalline nature of $\mathrm{ZnO}$. The average grain size calculated from Scherrer"s formula was about $19 \mathrm{~nm}$.

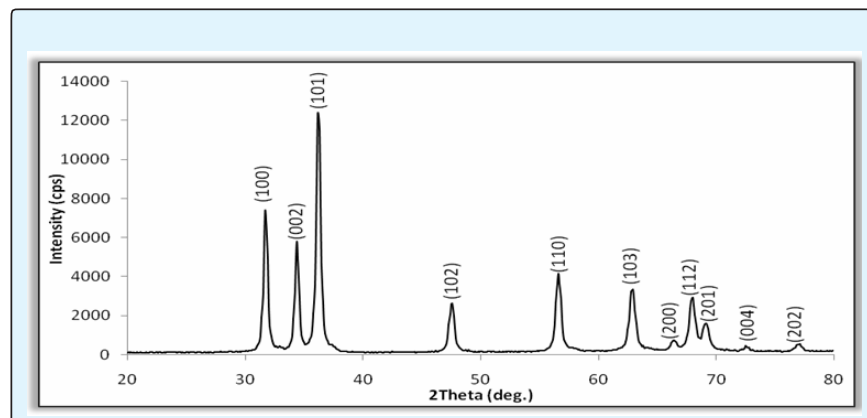

Figure 1: X-ray diffractogram of nanocrystalline $\mathrm{ZnO}$ thick film.

\section{Scanning Electron Microscopy (SEM)}

Scanning electron micrograph, in Figure 2 is showing topography of the film surfaces. The morphology of the particles was roughly spherical in shape. The particles are observed to be agglomerated. Determination of particle size was found to be difficult. The microstructure of the film was therefore studied using transmission electron microscopy.

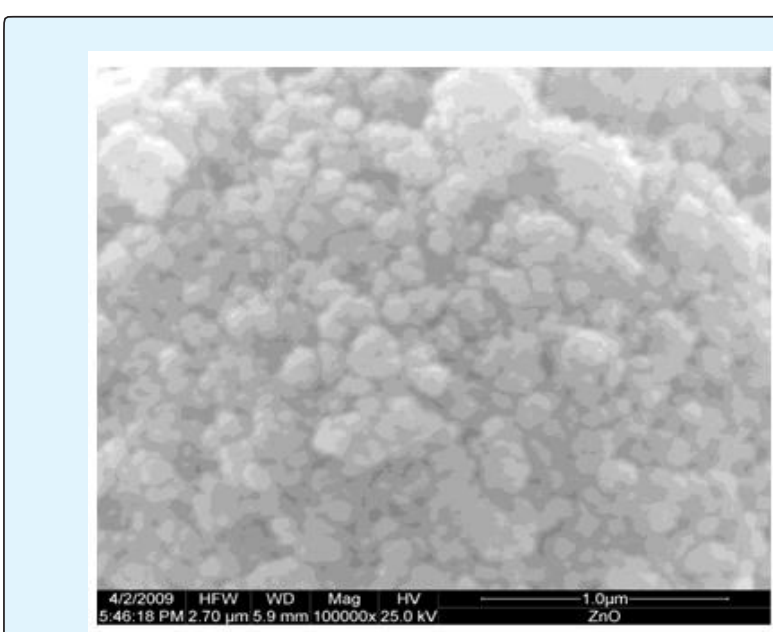

Figure 2: SEM images of the nanocrystalline $\mathrm{ZnO}$ thick film.

\section{Energy Dispersive Analysis of X-rays (EDAX)}

Elemental compositions of nanocrystalline $\mathrm{ZnO}$ thick film (Table 1).

\begin{tabular}{|c|c|c|c|c|}
\hline & \multicolumn{2}{|c|}{ Observed } & \multicolumn{2}{c|}{ Stoichiometric } \\
\hline Element & mass \% & at \% & mass \% & at \% \\
\hline $\mathrm{Zn}$ & 86.5 & 59.46 & 80.34 & 50 \\
\hline 0 & 13.5 & 38.94 & 19.66 & 50 \\
\hline $\mathrm{ZnO}$ & 100 & 100 & 100 & 100 \\
\hline
\end{tabular}

Table 1: Elemental compositions of nanocrystalline $\mathrm{ZnO}$ thick film.

Theoretically expected mass \% of $\mathrm{Zn}$ and $\mathrm{O}$ in stoichiometric $\mathrm{ZnO}$ are expected to be 80.3 and 19.7 respectively. The observed values of mass $\%$ of $\mathrm{Zn}$ and 0 are represented in Table 1 . It is clear from table that as prepared $\mathrm{ZnO}$ powder was observed to be nonstoichiometric. The powder was found to be oxygen deficient. Sensing performance of the oxygen deficient films was reported to be better as compared to the stoichiometric counterpart. 


\section{Nanomedicine \& Nanotechnology Open Access}

\section{Transmission Electron Microscopy (TEM) and Electron Diffraction}

TEM technique was used to know exact grain size, shape and distribution of the crystallites associated with the powder. It is clear from TEM image (Figure 3) that there are uniformly distributed spherical or elliptical shaped grains with the average grain size of $20 \mathrm{~nm}$.

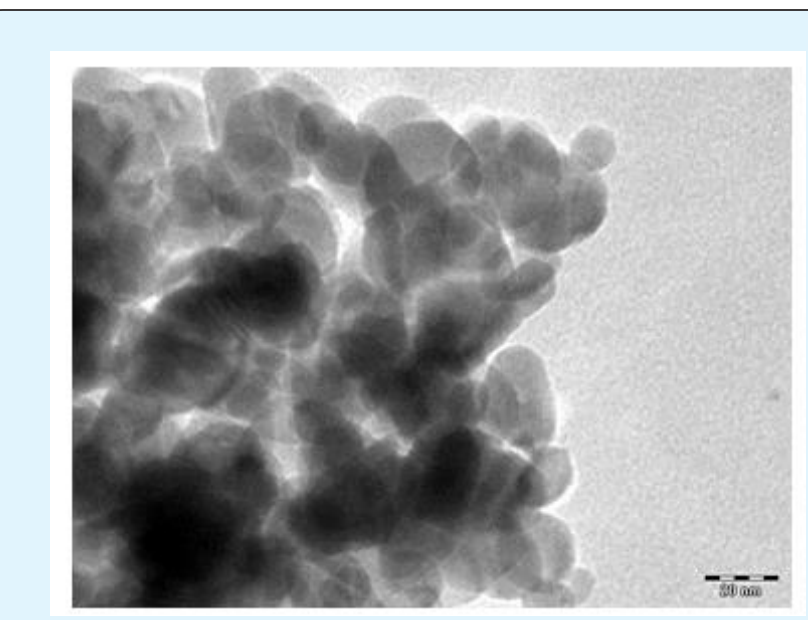

Figure 3: TEM images of the nanocrystalline $\mathrm{ZnO}$ thick film.

\section{Sensing performance of the sensors}

\section{Measurement of Response}

Response (S) is defined as the ratio of the change in conductance of the sensor on exposure of the conventional gas /simulant to the original conductance in air. It is given as:

$$
\mathrm{S}=\left(\mathrm{I}_{\mathrm{g}}-\mathrm{I}_{\mathrm{a}}\right) / \mathrm{I}_{\mathrm{a}}
$$

where $I_{a}$ and $I_{g}$ are the conductances of the sensor on exposure of air and conventional gas/simulant respectively.

\section{Gas Response with Operating Temperature of Sensor}

Figure 4 shows the variation of gas response with operating temperature of nanocrystalline $\mathrm{ZnO}$ sensor (thick film) for 1000 ppm LPG, $\mathrm{H}_{2}, \mathrm{CO}_{2}, \mathrm{NH}_{3}, \mathrm{C}_{2} \mathrm{H}_{5} \mathrm{OH}$ and $\mathrm{Cl}_{2}$. It is clear from figure that nanocrystalline $\mathrm{ZnO}$ showed largest response to $\mathrm{NH}_{3}$ at $300^{\circ} \mathrm{C}$ as compared to responses of $\mathrm{C}_{2} \mathrm{H}_{5} \mathrm{OH} \& \mathrm{Cl}_{2}$ at $400^{\circ} \mathrm{C}, \mathrm{LPG} \& \mathrm{H}_{2}$ at $350^{\circ} \mathrm{C}$ and $\mathrm{CO}_{2}$ at $300^{\circ} \mathrm{C}$.

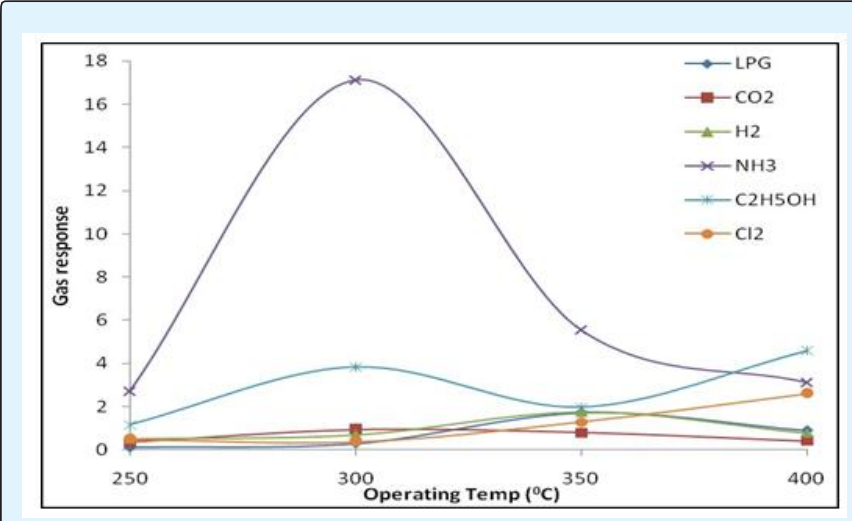

Figure 4: Variation of gas response with operating temperature of nanocrystalline $\mathrm{ZnO}$.

\section{Simulant Response with Operating Temperature}

Figure 5 shows the variation of simulant responses with operating temperature of nanocrystalline $\mathrm{ZnO}$ thick film on exposure of $2 \mathrm{ppm}$ DMMP, CEES and CEPS. It is clear from figure that pure $\mathrm{ZnO}$ gives temperature dependent sensing to various simulants. It shows better response to DMMP than to CEES at $450^{\circ} \mathrm{C}$ while better response to CEES than to DMMP at $400^{\circ} \mathrm{C}$. The same sensor could be used to detect DMMP and CEES simulants just by tuning the corresponding operating temperature. Different simulant have different chemical activity with the sensor surface at particular temperature, i.e., different simulants have different energies of adsorption and desorption and also different energy required to decompose different simulants. Good simulant response may be due to nanocrystalline nature of $\mathrm{ZnO}$.

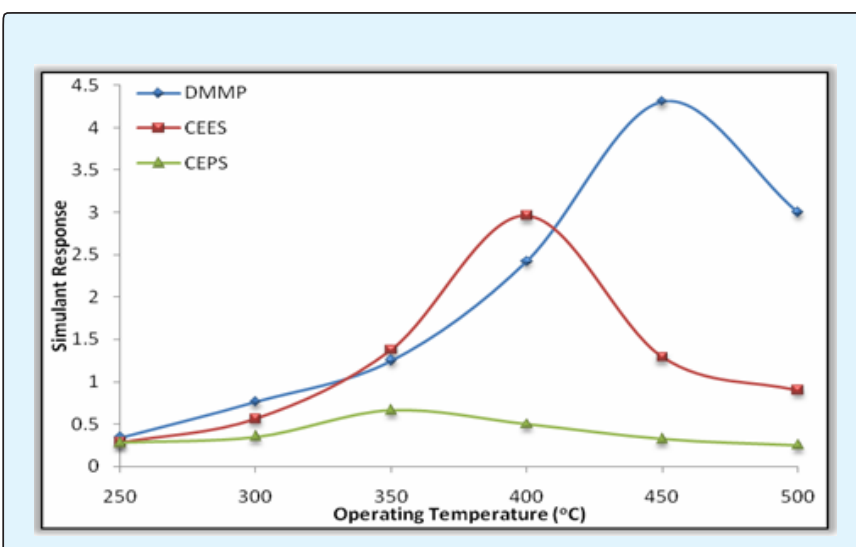

Figure 5: Variation of simulant response with operating temperature of nanocrystalline $\mathrm{ZnO}$ film. 


\section{Nanomedicine \& Nanotechnology Open Access}

\section{Response and Recovery of the Sensor}

The time taken for the sensor to attain $90 \%$ of the maximum decrease in resistance on exposure to target is defined as response time. The time taken for the sensor to get back $90 \%$ of original resistance is the recovery time. Figure 6 shows the response and recovery of the nanocrys talline $\mathrm{ZnO}$ thick film sensor at an operating temperature $300^{\circ} \mathrm{C}$. The response was quick $(\sim 17 \mathrm{~s})$ and the recovery was fast $(\sim 37 \mathrm{~s})$. The neglibale quantity of the surface reaction products and their high volatility explain the quick response and fast recovery to $\mathrm{NH}_{3}$.

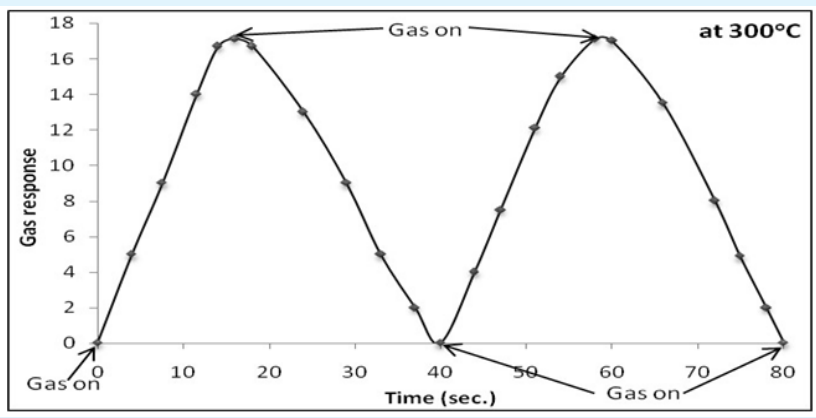

Figure 6: Response and recovery of nanocrystalline $\mathrm{ZnO}$ thick film sensor.

Figure 7 shows the response and recovery of pure nanocrystalline $\mathrm{ZnO}$ thick film to DMMP. The $90 \%$ response and recovery levels were attained within $\sim 3$ and $\sim 7$ seconds respectively.

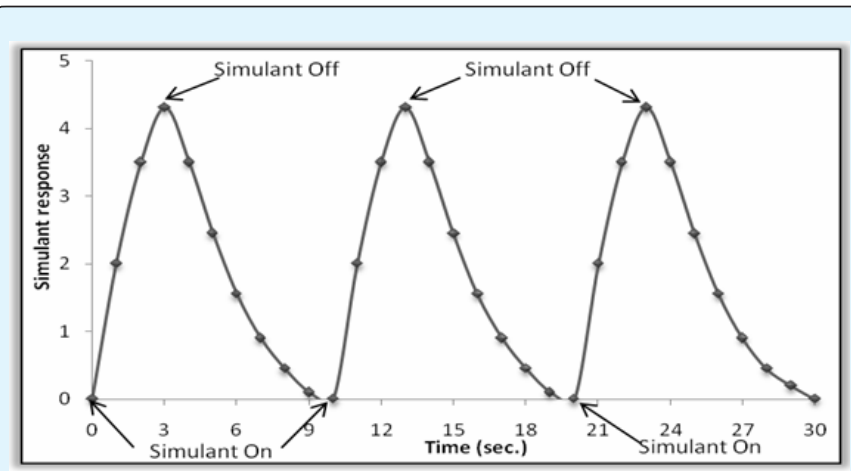

Figure 7: Response and recovery of nanocrystalline $\mathrm{ZnO}$ thick film sensor.

\section{Conclusions}

1. Ultrasonic atomization technique was used to prepared nanostructured $\mathrm{ZnO}$ powder

2. XRD analysis confirmed that the powder to be of $\mathrm{ZnO}$ with wurtzite structure.

3. SEM image showed roughly spherical particles with average size of $29.75 \mathrm{~nm}$.

4. Average grain size calculated from XRD was $19.25 \mathrm{~nm}$ and from TEM it was $20.10 \mathrm{~nm}$.

5. The response of nanocrystalline $\mathrm{ZnO}$ based sensor was observed to be largest to $\mathrm{NH}_{3}$ at $300^{\circ} \mathrm{C}$.

6 . The sensor showed very quick response $(17 \mathrm{~s})$ and fast recovery time (37s) to $\mathrm{NH}_{3}$ gas.

7. The response of nanocrystalline $\mathrm{ZnO}$ thick film sensor to DMMP at $450^{\circ} \mathrm{C}$ was larger than the response to CEES. Response to CEPS was observed to be smallest.

8. The quick response (3s) and fast recovery (7s) were the important features of the nanocrystalline $\mathrm{ZnO}$ sensor.

9. The nanocrystalline $\mathrm{ZnO}$ could be a promising candidate as a sensor for detecting conventional gas and simulants of chemical warfare agents.

\section{Acknowledgements}

The authors are thankful to the Head, Department of Physics and Principal, Pratap College, Amalner for providing laboratory facilities for this work. The financial support for this work from the Department of Information Technology and Defence Research Development Organization (DRDO), Government of India, New Delhi are gratefully acknowledged.

\section{References}

1. Moseley $P$ (1992) Materials selection for semiconductor gas sensors. Sensors Actuators B Chemical 6(1-3): 149-156.

2. Bari A, Shinde M, Deo V, Patil L (2009) Effect of solvents on the particle morphology of nanostructured ZnO. Indian J Pure Appl Phys 47(1): 24-27.

3. Ohya Y, Niwa T, Ban T, Takahashi Y (2001) Thin Film Transistor of ZnO Fabricated by Chemical Solution Deposition. Jpn J Appl Phys 40(1): 297-298.

4. Chawla A, Kaur D, Chandra R (2007) Structural and optical characterization of $\mathrm{ZnO}$ nanocrystalline films deposited by sputtering. Opt Mater 29(8): 995-998.

5. Shinde V, Gujar T, Lokhande C (2007) LPG sensing properties of $\mathrm{ZnO}$ films prepared by spray pyrolysis 


\section{Nanomedicine \& Nanotechnology Open Access}

method: Effect of molarity of precursor solution. Sens Actuators B Chemical 120(2): 551-559.

6. Patil LA, Bari AR, Shinde MD, Vinita Deo, Amalnerkar DP (2011) Synthesis of ZnO nanocrystalline powder from ultrasonic spray pyrolysis technique, characterization and its application in gas sensing. IEEE Sensors Journal 11(4): 939-946.

7. Patil LA, Bari AR, Shinde MD, Vinita Deo, Kaushik MP (2012) Detection of dimethyl methyl phosphonate - a simulant of sarin: the highly toxic chemical warfare using platinum activated nanocrystalline $\mathrm{ZnO}$ thick films. Sensors and Actuators B: Chemical 161(1): 372380.

8. Sberveglieri G, Baratto C, Comini E, Faglia G, Ferroni $M$, et al. (2009) Semiconducting tin oxide nanowires and thin films for chemical warfare agents detection. Thin Solid Films 517(22): 6156-6160.
9. Patil LA, Bari AR, Shinde MD, Vinita Deo (2009) Ultrasonically prepared nanocrystalline $\mathrm{ZnO}$ thin films for highly sensitive LPG sensing. Sens Actuators B 149(1): 79-86.

10. Patil LA, Bari AR, Shinde MD, Vinita Deo, Kaushik MP (2010) Effect of precursor concentrations on structural, microstructural and optical properties of nanocrystalline $\mathrm{ZnO}$ powder synthesized by ultrasonic atomization technique. Physica Scripta 82(3): 035601-035606.

11. Patil LA, Wani PA, Sainkar SR, Mitra A, Phatak GJ, et al. (1998) Studies on 'fritted' thick films of photoconducting CdS. Mater Chem Phys 55(1): 79-83.

12. JCPDS data card no 5-664.

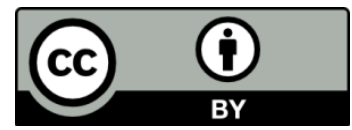

